\title{
Mechanics of Early Age Cemented Paste Backfill
}

\author{
M. Helinski The University of Western Australia, Australia
}

A.B. Fourie Australian Centre for Geomechanics, Australia

M. Fahey The University of Western Australia, Australia

\section{INTRODUCTION}

Between December 2003 and December 2004 there were reportedly at least six paste fill barricade failures worldwide, with each of these failures resulting in an inrush of fill to the mine workings. Many of these failures are considered to be a result of misunderstanding the mechanisms associated with the consolidation of paste fill during placement. This paper outlines the importance of consolidation in assessing mechanisms associated with the early age behaviour of paste fill. To illustrate the importance of consolidation, a series of numerical simulations have been presented, including a completely drained, an undrained and a coupled analysis. As the in situ development of effective stress will be dominated by the rate of consolidation, understanding this behaviour will also assist in replicating in situ curing conditions.

A one dimensional consolidation model capable of simulating the consolidation of a cemented paste fill is presented. A parametric study is undertaken to illustrate the influence of consolidation mechanisms specifically related to cemented paste fill. Finally, the model output is compared with a set of in situ pore water pressure (PWP) measurements to illustrate the relevance of the assumed mechanisms.

\section{BACKGROUND}

Paste filling is a process utilised in many underground mining operations. This involves the filling of tall underground voids with a free flowing combination of mine tailings, water and cement. This process will often result in over $10 \mathrm{~m}$ vertical rise per day (Le Roux et al., 2004) with silt-size material. This material is contained at openings using structural barricades. While different sites will have different particle size distributions and different filling rates, the combination of rapid filling rate and fine grained material means that the self weight loading condition may often be close to undrained.

The key points to note with regards to the undrained loading of mine backfill are: there will be no change in volume; there will be no change in vertical effective stress; there will be no change in horizontal effective stress; and an increment of vertical total stress produces an equal increment of horizontal total stress. To the authors' knowledge, analysis of undrained filling (taking account of these characteristics) has not previously been rigorously addressed.

It is not the aim of this paper to state that filling with paste fill will always create drained or undrained conditions. Rather, it is to suggest that the rate will often create conditions that are somewhere between these 
two extremes. The purpose of the paper is to demonstrate the significant variation in stope stresses and barricade loads due to consolidation and to emphasise the importance of understanding the PWP behaviour when assessing minefill (and barricade) stability.

\section{STRESS ANALYSIS}

\subsection{Numerical modelling}

In order to demonstrate the significance of the drainage conditions on the stress distribution within a pastefill stope, a series of numerical experiments have been carried out using the program numerical analysis program FLAC. The paste fill has been modelled as a Mohr Coulomb material with no tensile strength. A simplified plane strain stope geometry has been adopted, where the fill at the stope boundary has been fixed against movement. The impact of PWP has been included in the undrained case by configuring the analysis to include groundwater but 'turning the flow off'. This ensures an increase in PWP due to the application of total stress but does not allow any of this pressure to dissipate. The drained case has been analysed in a similar way, but in this case all pore water pressures are maintained at zero. It should be noted that in both cases the barricade has been assumed to be free draining (i.e. the PWP immediately behind the barricade has been assumed to be zero).

The modelled plane-strain stope is $20 \mathrm{~m}$ wide and $50 \mathrm{~m}$ tall. In order to include realistic material properties, the values quoted (Rankine et al., 2001) for fully hydrated material stiffness have been adopted. These include a Young's modulus (E) of $60 \mathrm{MPa}$ and a Poisson's ratio $(v)$ of 0.25 . These parameters equate to a shear modulus $(\mathrm{G})$ of $24 \mathrm{MPa}$ and a drained bulk modulus $(\mathrm{K})$ of $40 \mathrm{MPa}$. It should be noted that the stiffness being adopted in this analysis is the fully hydrated stiffness, which would provide the highest possible amount of stress redistribution to the surrounding rockmass. The strength parameters adopted are a cohesion (c) of $25 \mathrm{MPa}$ with a friction angle $(\phi)$ of $25^{\circ}$.

The purpose of adopting this very large cohesion is to illustrate that; provided the material remains elastic, the material stiffness will dictate the degree of load that is redistributed to the surrounding rockmass, regardless of the strength. Limit state methods, (Winch, 1999 and Aubertin et al., 2003), assume that the material at the fill/rock interface can mobilise its full strength and calculate the stress distribution in accordance with this assumption. In a stable situation, the material strength may not all be mobilised, which would violate this assumption. This would be of particular relevance during undrained loading as discussed in Section 3.2. As a result, the use of limit state methods to simulate stresses during filling will often underestimate the in situ stresses and barricade loads.

Figure 1 shows the total vertical stress down the centerline of the stope for both the drained and undrained cases. Also shown in Figure 1 is the self weight stress plotted against depth. Inserted into this figure are 
FLAC output figures showing contours of total vertical stress for the half spaces modelled. Contours for both drained and undrained cases have been presented. The contour interval on both plots is $100 \mathrm{kPa}$.

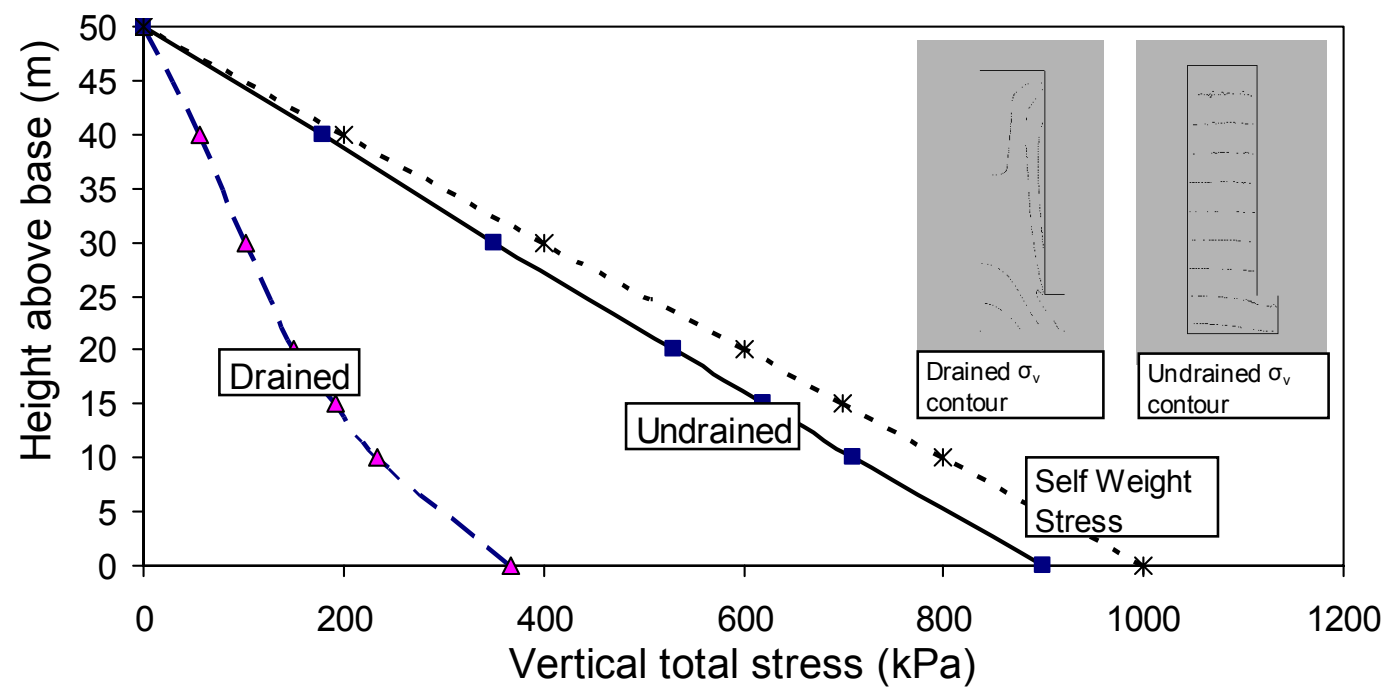

\section{Figure 1 Total vertical stress along stope centreline}

It may be seen that the total vertical stress in the undrained case is very close to the total overburden stress while in the drained case there are significantly lower stresses indicating that some stress redistribution is occurring. This lack of stress redistribution is further illustrated in the vertical stress contour plots, which show the total vertical stress being close to constant in the horizontal direction for the undrained case.

The FLAC model used to assess the stresses within the stope has also been used to demonstrate the impact of consolidation on barricade loads. Figure 2 shows the predicted total horizontal stress distribution on a $6 \mathrm{~m}$ barricade. The barricade has been modelled as being $6 \mathrm{~m}$ along a plane strain drawpoint. This figure indicates that the assumption of undrained filling will result in a barricade stress of approximately $800 \mathrm{kPa}$ while the drained analysis indicates a barricade load of approximately $80 \mathrm{kPa}$.

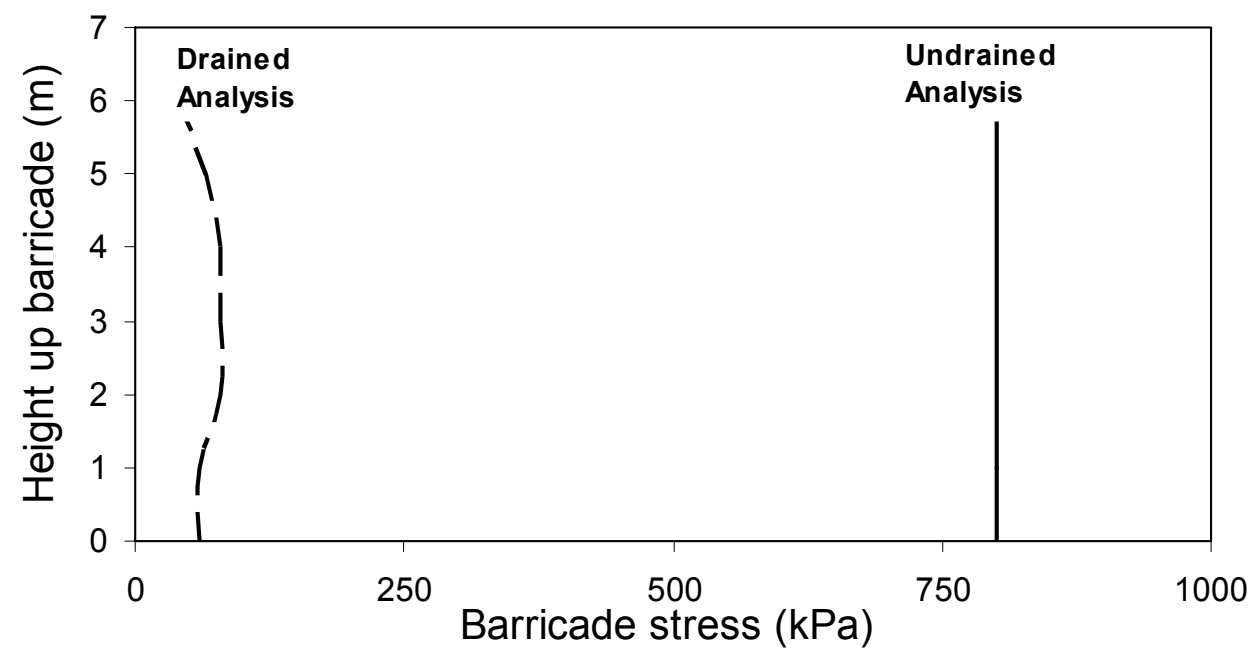

Figure 2 Barricade loads using undrained and drained analysis 
Overall, this analysis indicates that if undrained loading is occurring, vertical stresses in the stope are likely to be close to total overburden stresses regardless of cement bond strength. Furthermore, should undrained conditions exist at the base of the stope, the horizontal total stresses will be approximately equal to the vertical total stress. However, should a drained conditions exist, the estimated stresses will be much lower.

\subsection{Discussion of modelling results}

During elastic loading, the distribution of stress will be in accordance with the relative stiffness i.e. the ratio between the vertical compressive stiffness and the shear stiffness. Shear stress $(\tau)$, which is required to generate stress redistribution to the surrounding rockmass, can only be generated if the element is subjected to a shear strain $(\gamma)$. The mobilised shear stress may be related to shear strain via Equation 1:

$$
\tau=\mathrm{G} \gamma
$$

where $\mathrm{G}$ is the shear stiffness of an element. If a soil is loaded undrained, the compressive stiffness will be the bulk stiffness of water rather than that of the soil skeleton. For comparison purposes, the bulk modulus of water is $2 \mathrm{GPa}$ while the (drained) bulk modulus of a fully hydrated cemented paste fill will be in the order of $40 \mathrm{MPa}$, making soil loaded in an undrained manner effectively incompressible. Therefore, when the soil is loaded in an undrained manner there can be no vertical compression and therefore no induced shear strain, thereby preventing development of shear stress. With no shear stress at the interface, there can be no stress redistribution. As consolidation takes place and the material is allowed to displace vertically (due to the expulsion of pore water), shear stress will be mobilised allowing for some redistribution of stress to the surrounding rockmass, thereby allowing some arching to develop.

The lateral earth pressure coefficient $\left(\mathrm{K}_{\mathrm{o}}\right)$ is defined in terms of effective stress, such that the total horizontal stress $\left(\sigma_{\mathrm{h}}\right)$ may be calculated as:

$$
\sigma_{\mathrm{h}}=\sigma_{\mathrm{h}}^{\prime}+\mathrm{u}=\mathrm{K}_{\mathrm{o}} \sigma_{\mathrm{v}}^{\prime}+\mathrm{u}
$$

where $\sigma_{v}^{\prime}$ is the vertical effective stress, and $u$ is the PWP (which is isotropic).

Therefore, if undrained loading is occurring at the drawpoint, the horizontal total stresses will be equal to the PWP, which is in turn equal to the vertical total stress (as the effective stress is zero). The combination of the high vertical total stresses within the stope and undrained condition at the drawpoint will create large barricade loads as seen in Figure 2 for the undrained case.

\subsection{Consolidation analysis}

In order to demonstrate the impact of consolidation on barricade loads, another simplified FLAC analysis was carried out in which the material was placed undrained and allowed to drain, with the top surface and barricade being the drainage boundaries. The paste fill was assigned strength and stiffness values of fully 
hydrated material and the permeability was set to a very high value to ensure fast consolidation. During the consolidation process the PWP at the centre of the stope floor was monitored as well as vertical stresses along the stope centre line and the barricade stresses. Figure 3 illustrates how the stope stresses and barricade stresses change as a result of consolidation. The degree of consolidation is defined as the amount of pore water pressure dissipated (from an element in the centre of the stope floor) relative to the PWP from the initial undrained loading. Figure 3(a) shows the vertical stress at different elevations along the centre of the stope for various degrees of consolidation at that depth while Figure 3(b) illustrates the change in barricade stress against the degree of consolidation at the stope floor. Figure 3(a) illustrates quite clearly that as the pore water pressure dissipates the degree of stress redistribution (arching) increases and the total vertical stresses in the stope reduce. Figure 3(b) illustrates that, in addition to a reduction in vertical stress within the stope, the reduction of pore water pressure at the drawpoint will act to increase effective stress, reducing horizontal total stresses and reducing barricade loads.

\subsection{Implications for sample preparation}

In addition to stope stresses and barricade loads, the degree of consolidation will have a major impact on the state at which in situ material will be cured. Work has shown that the curing void ratio and effective stress state influence the properties of cemented soil. (Consoli et al., 2000; Li and Aubestin, 2003; Rotta et al., 2003). Tests have shown that the application of effective stress during curing can create a significant increase in the final strength of cemented minefill material (Blight, 2000).
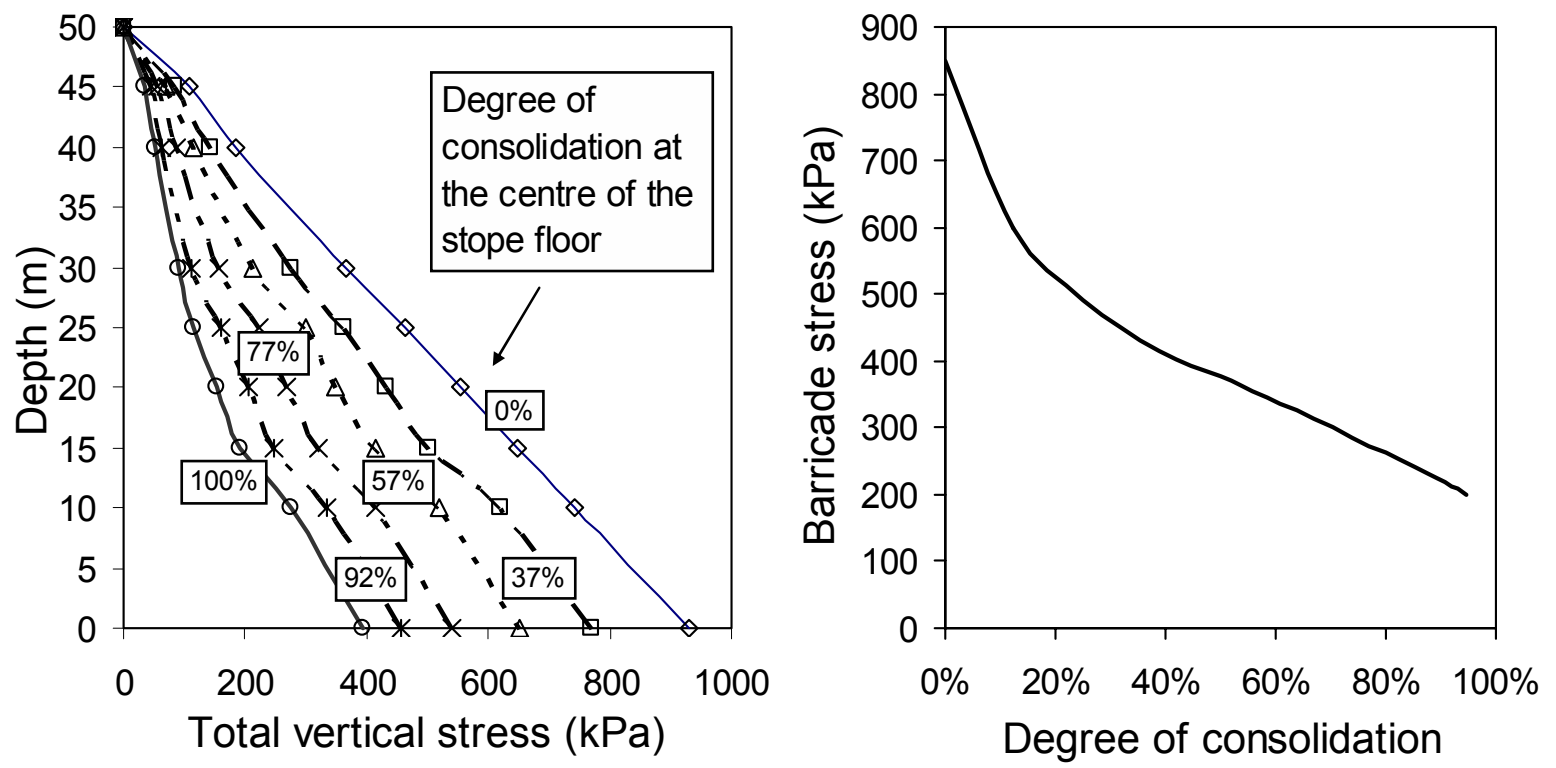

\section{Figure 3 (a) Vertical stress along stope centre line; (b) Barricade loads versus degree of consolidation}

If it is assumed that filling is being carried out in an undrained manner, laboratory samples should be cured under zero effective stress. However, if it is assumed that filling is carried out in a drained manner (i.e. no excess pore water pressure increase) the addition of overlying fill will result in a proportional increase in 
effective stress during curing. Therefore, samples should be cured under this increasing effective stress, (Le Roux et al., 2002 and Belem et al., 2002). In a partially drained situation, the rate of increase in effective stress will be equal to the rate of PWP dissipation, so that if the rate of PWP dissipation can be predicted, effective stress may be applied to the specimen at the same rate to replicate in situ conditions. By curing samples under zero effective stress (as is usually the case) laboratory samples will most often provide conservative strengths when compared with in situ material that has been cured under an effective stress. Techniques for curing samples under the same effective stress as in the field are beyond the scope of this paper however this process may not be as complex as staged triaxial loading.

\section{COUPLED ANALYSIS}

From what has been presented, it can be seen that the presence of pore water pressure will have a dramatic effect on the stress distribution within a paste filled stope. Unless the assumption of drained or undrained loading can be justified, it is suggested that the only reasonable approach would be a fully coupled analysis. In this context, "fully coupled" means that consolidation/drainage is properly modelled as the filling proceeds, including in this analysis the stiffness and permeability changes that occur as the voids ratio reduces. However, for cemented backfill, it also means incorporating the hydration process in the analysis.

Thus, in addition to conventional consolidation characteristics there will be aspects specifically related to the hydration of cement that will have an impact on the consolidation behaviour of paste fill. The authors are currently undertaking a research project to further the understanding of these aspects and provide a tool that may be used to model the consolidation behaviour of paste and hydraulic fills. Research to date has identified the following as being the most important aspects to consider when assessing the consolidation behaviour of cemented mine backfill:

- Stiffness and strength change with time: The increase in strength and stiffness during hydration will increase the rigidity of the matrix. With an increased stiffness the soil matrix will have to deform less to generate an increase in effective stress and therefore less water volume will need to be expelled to dissipate pore water pressures. This will increase the rate of consolidation.

- Permeability as a function of voids ratio and cement gel growth: As the cement hydrates grow they will fill in void space that is utilized for flow, thereby reducing the permeability. In addition, the reduction in void space due to consolidation will also create reduced permeability. This reduction in permeability will decrease the rate of consolidation.

- Damage due to plastic strain: If the material is exposed to plastic strain during hydration, cement bonds that are forming may break down, reducing the materials strength and stiffness. An algorithm (Carter and Liu, 2005) for naturally-cemented soil has been adopted to represent this behaviour. 
- Strength and stiffness as a function of void ratio: It has been well documented (Consoli et al., 2000, Li and Aubertin, 2003 and Rotta et al., 2003) that the strength and stiffness of cemented soils depend on the density (or void ratio) at the time of hydration. An exponential function similar to that presented by Rotta et al., has been used to relate strength to cement addition and density. (Rotta et al., 2003).

- Reduction in Poisson's ratio as a function of time: Zuh and Clark showed that during cementation the Poisson's ratio (or lateral earth pressure coefficient, $\mathrm{K}_{\mathrm{o}}$ ) can reduce significantly (Zuh and Clark, 1993). An empirical relationship, developed by the authors and fitted to the Zuh and Clark data, has been implemented. This will have a major impact on horizontal stresses as well as the ratio between shear and bulk modulus both aspects that are important for arching.

- Self desiccation: The process of self desiccation has been well documented with respect to its impact on concrete structures. The basis of this process is that following cement hydration, the resulting hydrated volume is less than that of the unhydrated constituents. Authors such as Powers, Hau, Bentz and Brouwers have investigated the impact of this mechanism on the shrinkage of conventional concrete structures (Powers, 1947; Hau et al., 1995; Bentz, 1995; and Brouwers, 2004). With respect to cemented minefill, this volume reduction will assist in the dissipation of PWP. It is important to note that the degree of PWP dissipation will be related to both the consumption of water volume (due to hydration) and the stiffness of the soil matrix. Further detail relating to the self desiccation of cemented paste fill (Helinski et al., 2006).

A computer program 'MinTaCo' has been developed for carrying out fully coupled one-dimensional consolidation analysis of uncemented tailings and is published elsewhere (Seneviratne et al., 1996). This program has been modified by the authors to incorporate the aspects related to cement hydration described above. The relationships that have been adopted are based on fundamental soil mechanics principles and are therefore suitable for both paste and hydraulic fill.

The results from some parametric studies with this model are presented in Figure 4. This shows the evolution with time of the self-weight total stress (solid line) and PWP (dashed lines) at a point $2 \mathrm{~m}$ above the floor of the stope during a filling cycle. The filling cycle involves the deposition of $8 \mathrm{~m}$ of fill in 1 day followed by a rest period of 36 hours, followed by the subsequent filling of the remainder of the stope at a rate of $0.4 \mathrm{~m}$ per day. The purpose of this parametric study was to illustrate the impact of the cementation characteristics mentioned above on the rate of consolidation. The following cases were analysed:

- Filling with uncemented fill ( $0 \%$ Cement): To demonstrate the impact of neglecting cementation during consolidation analysis.

- Filling with 5\% cemented fill without Self Desiccation: To demonstrate the impact of increasing stiffness and reducing permeability on the consolidation behaviour. 
- Filling with 5\% cemented fill with Self Desiccation: To illustrate the impact of self desiccation on the consolidation behaviour.

Figure 4 illustrates that, even when the self-desiccation mechanism is not incorporated, the increase in stiffness due to cementation outweighs the reduction in permeability due to hydration, and, as a result, the maximum pore pressure generated is less, and the subsequent rate of pore pressure dissipation is greater, than if no cementation occurs. In addition, when self-desiccation is included, this can be seen to have a dramatic effect on the consolidation behaviour, with lower peak pore pressures generated, and a faster rate of pore pressure dissipation than for the other two cases. As it has already been shown that barricade loads are significantly influenced by pore pressure levels, it can be concluded that proper analysis of the process requires the use of analysis methods that fully couple the consolidation behaviour with the cementationinduced strength, stiffness gain and self-desiccation.

The performance of the one-dimensional model has been compared with in situ PWP measurements from the Cayeli mine in Turkey in Figure 5. Typical paste fill parameters were input into the model along with the actual filling rate and placement densities. Figure 5 shows the evolution of measured PWP (at the base of the stope during filling) as well as predicted PWP, against time. Also shown is the applied self weight total stress against time.

The modelling results compare well with the in situ measurements during the early stages of filling. This is an indication that the assumed mechanisms are reasonable. It can be seen that during the early stages (up to approximately 0.5 days) the PWP increases at the same rate as the total stress, indicating completely undrained loading. During this stage there is no effective stress and no cohesive bonding, therefore the material has no strength and no effective (matrix) stiffness. As the matrix has no stiffness, the water volume consumption due to self desiccation will cause an equivalent soil matrix compression and result in no PWP reduction. At approximately 0.5 days the paste appears to reach initial set where the matrix begins to develop cement-induced stiffness and strength.

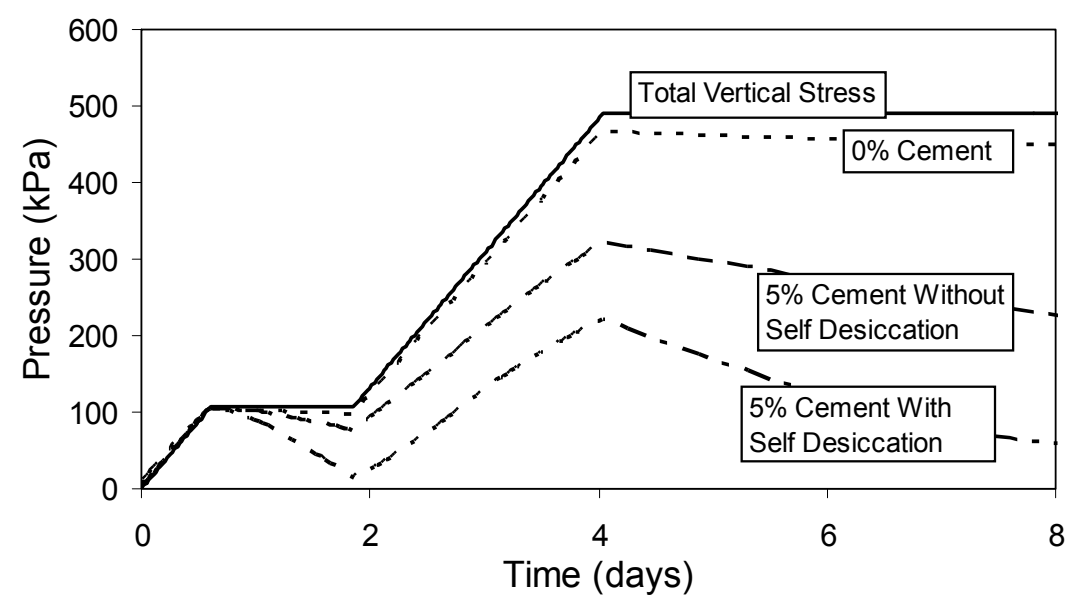

Figure 4 Parametric study indicating cementation impact 
With a stiff soil matrix, water volume removed as a result of self desiccation will not be accompanied by an equivalent matrix compression and hence the PWP will drop as effective stress is transferred into the soil matrix. This concept has been explained in more detail elsewhere (Helinski et al., 2006).

The predicted and measured PWPs in Figure 5 tend to diverge during the second stage of filling (around 2 days). After 2 days it can be seen that there has been a significant reduction in PWP, and hence an increase in effective stress. With the development of effective stress it is likely that some stress redistribution (arching) has now commenced and as a result the applied total stress (due to filling) may not all be transferred to the location of the piezometer. Therefore, the measured pressure increase from then onwards is less than the modelled result. Since the model is only one dimensional, the impact of stress redistribution is not accounted for. The aim of the next phase in this work will be to implement the material characteristics into a three dimensional program so that effects such as arching can be accounted for.

\section{CONCLUSIONS}

This paper has shown that the degree of consolidation will have a dramatic impact on the stress distribution within a paste fill stope and on barricade loads. An understanding of the consolidation process will therefore be essential to understand the mechanisms associated with stress distributions during filling operations. Various industry standards, for example those suggested by Potvin (Potvin et al., 2005), have been developed to limit barricade loads, but without the type of rigorous approach presented here, there is no guarantee that such standards are always suitably conservative. The consolidation analysis of cemented paste fills is a rather complex process, requiring models that incorporate important characteristics specifically associated with cement hydration, coupled with the normal consolidation process. A one-dimensional consolidation model of this type has been presented and shown to compare well with in situ pore water pressure measurements during the early stages of filling. This model indicates that some pore water pressure dissipation is taking place and the increase in effective stress associated with this PWP dissipation is generating some degree of arching.

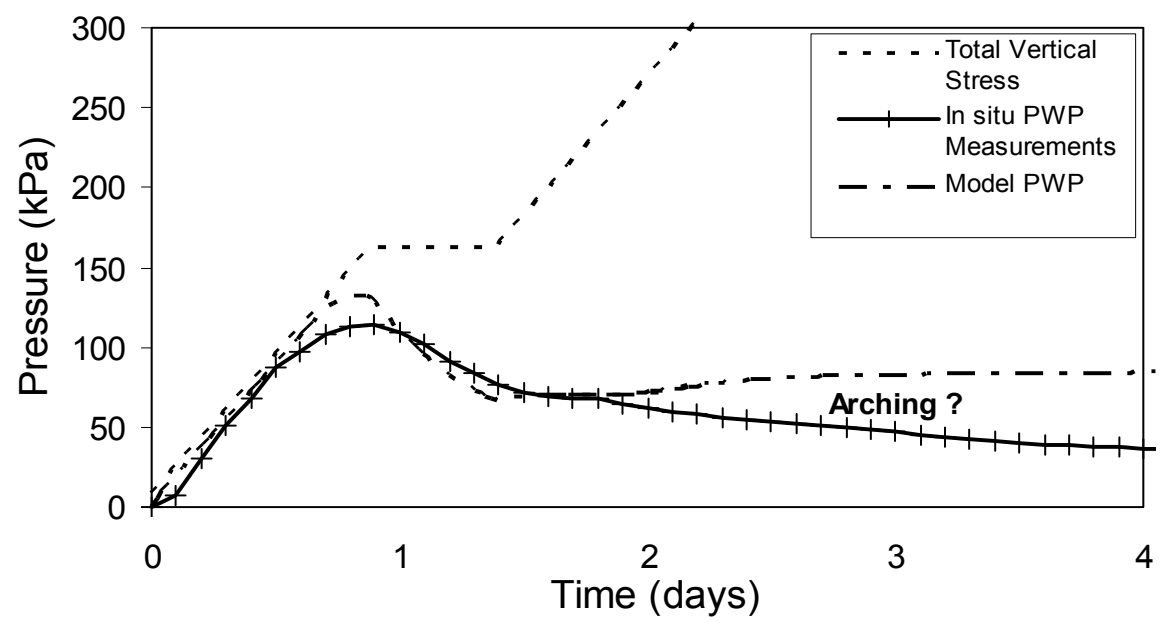

Figure 5 Data from Cayeli Mine (Turkey) compared with results from the 1D model 
The application of consolidation theory can help to further our understanding of both stress distributions and material strength evolution.

\section{ACKNOWLEDGEMENTS}

The authors would like to thank CBI, owners of Cayeli Mine, and AMC Consultants for gathering and supplying the in situ monitoring information that is used in Figure 5 of this document, and also MERIWA (the Minerals and Energy Research Institute of Western Australia) for contributing financially to this research.

\section{REFERENCES}

Aubertin, M., Li, L., Arnoldi, S., Belem, T., Bussiere, B., Benzaazoua, M. and Simon, R. (2003) Interaction between backfill and rock mass in narrow stopes. Soil and Rock America, Vol.1, pp. 1157-1164.

Bentz, D.P. (1995) Three-dimensional computer simulation of portland cement hydration and microstructure development. J Am Ceram Soc 80.

Belem, T., Benzaazoua, M., Bussiere, B. and Dagenais, A.M. (2002) Effect of settlement and drainage on strength development within mine paste backfill. Tailings and Waste '02.

Blight, G.E. (2000) The use of mine waste as structural underground support. Geoeng 2000, Melbourne.

Brouwers, H.J.H (2003) The work of Powers and Brownyard revisited: Part1. Cement and Concrete Research, Vol. 34, pp. 16971716.

Carter, J.P. and Liu, M.D. (2005) Review of the structured Cam Clay model., Soil Consitiutive Models: Evaluation, Selection and Calibration, ASCE, Geotechnical Special Publication No 128, pp. 99-132.

Consoli, N.C., Rotta, G.V. and Perietto, P.D.M. (2000) Influence of curing stress on the triaxial response of cemented soils, Géotechnique, Vol. 50, No 1, pp. 99-105.

Helinski, M., Fourie, A.B. and Fahey, M. (2006) The self-desiccation process in cemented mine backfill. Canadian Geotechnical Journal (submitted).

Hua, C., Acker, P. and Ehrlacher, A. (1995) Analysis and models of autogenous shrinkage of hardening cement paste. Cement and Concrete Research, Vol. 25, No. 7, pp. 1457-1468.

Le Roux, K. (2004) In situ properties and liquefaction potential of cemented paste backfill. PhD thesis, Graduate department of civil engineering, University of Toronto, Canada.

Li, L. and Aubertin, M. (2003) A general relationship between porosity and uniaxial strength of engineering materials. Canadian Journal of Civil Engineering, 30, pp. 644 -658.

Potvin, Y., Thomas, E. and Fourie, A. (2005) Handbook on Mine Fill, Australian Centre for Geomechanics.

Powers, T.C. and Brownyard, T.L. (1947) Studies of the physical properties of hardened portland cement paste. Bull.22, Res. Lab. of Portland Cement Association, Skokie, IL, U.S.A., reprinted from J. Am. Concr. Inst. (Proc.), Vol 43 (1947).

Rankine, R.M., Rankine, K.J., Sivakugan, N., Karunasena, W. and Bloss, M. (2001) Geotechnical characterisation and stability analysis of BHP Cannington paste backfill, Proceedings of 15th ISSMGE, Istanbul, Turkey, 1241-1244, Balkema, Rotterdam.

Rotta, G.V., Consoli, N.C., Perietto, P.D.M., Coop, M.R. and Graham, J. (2003) Isotropic yielding in an artificially cemented soil cured under stress, Géotechnique 53, No 1, pp. 493-501.

Seneviratne, N., Fahey, M., Newson, T.A. and Fujiyasu, Y. (1996) Numerical modelling of consolidation and evaporation of slurried mine tailings. International Journal for Numerical and Analytical Methods in Geomechanics, Vol. 20, No. 9, pp. 647-671.

Winch, C.M. (1999) Geotechnical characterisation and stability of paste backfill at BHP Cannington Mine. Undergraduate thesis, School of Engineering, James Cook University, Australia.

Zuh, F. and Clark, J.I. (1993) The effect of cementation of $\mathrm{K}_{\mathrm{o}}$ of sand. Proc of the third International Symposium on Offshore and Polar Engineering, Singapore, Volume Number 1, pp. 528-533. 